difference. In general, the higher the status, the less likely is it that wife or children will contribute to the family budget.

Secondly, in spite of family allowance, tax reliefs and social services, commitments vary disproportionately from family to family. It is traditional for the salary earner to maintain standards of dress and spending appropriate to his status. His expenditure on other commitments, notably housing and possibly education, will be greater than the wage-earner's.

The problem of differentials in industry is substantially the same problem as that faced by society as a whole: how to share out inadequate resources between the various claimants. More specifically, it is a problem of two competing demands : the demand for fair shares and the demand for incentives for skill, initiative, ingenuity and responsibility.

To such problems there is no perfect solution. Any system of rewards must of necessity be a compromise-a reconciliation of incompatible claims. The compromise should provide a reasonably satisfactory reward for those who, inside and outside industry, carry the responsibility for upholding and extending our standards of life. This problem of rewards for responsibility is less critical and less explosive than that of differentials due to skill. The skill differential compels attention because its holders are organized and can use the force of a pressure group to publicize their grievances and gain their ends. No such relief is open to responsibilityholders.

Nor can they hope for a reversal of the social revolution which has aggravated the narrowing of their differentials. It is most improbable that there will be any return to the inequalities of pre-war days. For the narrowing of differentials there is no remedy but acceptance.

There are a number of factors helping to predispose responsibility-holders to accept a reasonable narrowing of differentials. First, the rewards of responsibility are not limited to material benefits, in cash or in kind. There are satisfactions to be gained from the exercise of responsibility itself : from a sense of doing a worth-while job. The Americans, but not the British, have inculcated that feeling into their industrial management at all levels.

Secondly, differences in monetary reward matter less once basic provision is secured for the major needs of life. The hardships experienced by some salary earners are, on the long view, comparative only, and take on an unreal appearance when set beside the poverty the social revolution set out to cure.

Thirdly, many of the responsibility-holders of to-day have risen, often via State-aided education, from lower down the social scale. They are less conscious of a traditional standard of living that they must maintain.

If the narrowing continues, what are the dangers which may result from it ? There are two which are of real concern. One is that discontent may develop to the point where recruitment to positions of responsibility falls off and shortages occur; this appears to be the case with science teachers and with dentists. The other is that discontent will sap initiative and result in an immersion in unprogressive routine. Either, if it became widespread in industrial management, might make all the difference between a rising rate of productivity and a falling on $\theta$.

The great enemy of all differentials is inflation. The pay-packet of the wage earner, especially the less skilled, has on the whole kept ahead of prices. Inflation seems to have become an instrument for re-allocating the national income in favour of those with the biggest bargaining power. Worse than its effect on the immediate purchasing power of salaries is its effect on savings and pension funds.

A stabilization of prices is extremely desirable ; but it demands a self-restraint on the part of organized labour on which it would be unrealistic to rely. Many firms are already countering the narrowing responsibility differential by reviewing and reassessing staff salaries whenever now wage settlements are made. It would be an act of prudence and justice if all followed the lead of the best. Though the problem has not reached the proportions of a crisis, no one can view with equanimity any further narrowing of the differential based on responsibility.

'There are no quick solutions to the problem of rewarding responsibility. It is a matter for patient, long-term bargaining and readjustment.

\section{ATMOSPHERIC POLLEN}

I A. HYDE (Proc. Linn. Soc., 165, 2, 107; 1. 1955) has contributed new observations on the frequency of occurrence of pollen in the atmosphere which seem likely to be of interest to other investigators, including students of floral biology and quaternary botany, plant breeders, and members of the medical profession who are concerned with the problems of pollen allergy. The gravity slide method was used in making this pollen census. In the course of some ten years work, and making use of twelve different collecting stations, it has been possible to determine about 90 per cent of all the grains on the slides and to assign these to one or other of sixty-five different types.

The principal pollen types, listed in the order of their numerical importance, begin with the Gramineae with $48 \cdot 3$ per cent, followed by Ulmus with $11 \cdot 6$ per cent, Quercus 8.2 per cent, and so on down to Ranunculus with 0.41 per cent, and the sedges with 0.22 per cent. Variations in the pollen catch and in the preponderance of the different types from year to year in relation to weather conditions are considered and some interesting conclusions drawn. These are but indications of the several records presented and discussed.

On the subject of hay-fever, the author writes : "No kind of pollen is likely to evoke symptoms in a significant number of people unless it is formed and liberated in large quantities and is buoyant (so becoming and remaining airborne) and unless the source plant is widely and abundantly distributed. The results of the Cardiff pollen census, when considered in the light of this principle, show that the chief hay-fever plants of Great Britain are relatively few in number, viz., the grasses considered as a single group (since all kinds of grass pollen are generally assumed to be similarly antigenic), certain trees, viz., the oaks, ash, the elms and plane (notably in London), and certain herbs, viz., the plantains, docks and sorrels, and possibly common nettle. It is necessary before forming a diagnosis on a particular patient's hay-fever to be able to show that his symptoms coincided with or at least fell within the period during which he was actually inhaling the pollen concerned. For this purpose reference to the frequeney diagrams is essential." 